\title{
Improvements in Lung Diffusion Capacity following Pulmonary Rehabilitation in COPD with and without Ventilation Inhomogeneity
}

\author{
Pierachille Santus $^{a}$ Dejan Radovanovic ${ }^{b}$ Giovanni Balzano ${ }^{b}$ \\ Matteo Pecchiari ${ }^{c}$ Rita Raccanelli ${ }^{a}$ Nicola Sarno $^{d}$ Fabiano Di Marco $^{e}$ \\ Paul W. Jones ${ }^{f}$ Mauro Carone ${ }^{d}$ \\ a Department of Health Science, University of Milan, Pulmonary Rehabilitation Unit, Fondazione Salvatore Maugeri,

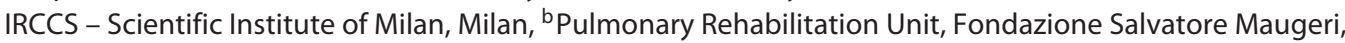 \\ IRCCS - Scientific Institute of Telese Terme, Benevento, ' Medical and Surgical Physiopathology and Transplants \\ Department, University of Milan, Milan, d Pulmunology Unit, Fondazione Salvatore Maugeri, IRCCS - Scientific \\ Institute of Cassano delle Murge, Bari, and e Department of Health Science University of Milan, Respiratory Unit,

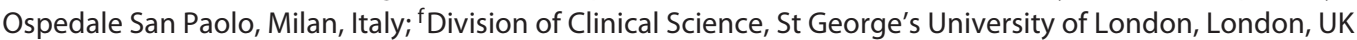

\section{Key Words}

Pulmonary rehabilitation - Lung diffusing capacity . Ventilation inhomogeneity · COPD · Transfer factor . Alveolar volume $\cdot$ Exercise tolerance

\begin{abstract}
Background: Lung diffusing capacity (DLCO) and lung volume distribution predict exercise performance and are altered in COPD patients. If pulmonary rehabilitation (PR) can modify DLCo parameters is unknown. Objectives: To investigate changes in DLCO and ventilation inhomogeneity following a PR program and their relation with functional outcomes in patients with COPD. Methods: This was a prospective, observational, multicentric study. Patients were evaluated before and after a standardized 3-week PR program. Functional assessment included body plethysmography, DLCO, transfer factor (KCO) and alveolar volume (VA), gas exchange, the 6-min walking test (6MWT) and exercise-related dyspnea. Patients were categorized according to the severity of airflow limitation and presence of ventilation inho-
\end{abstract}

mogeneity, identified by a VA/TLC $<0.8$. Results: Two hundred and fifty patients completed the study. Baseline forced expiratory volume in $1 \mathrm{~s}\left(\mathrm{FEV}_{1}\right) \%$ predicted (mean $\pm \mathrm{SD}$ ) was $50.5 \pm 20.1$ (76\% males); 137 patients had a severe disease. General study population showed improvements in 6MWT (38 $\pm 55 \mathrm{~m} ; \mathrm{p}<0.01)$, DLCO $\left(0.12 \pm 0.63 \mathrm{mmol} \times \mathrm{min}^{-1} \mathrm{kPa}^{-1}\right.$; $\mathrm{p}<0.01$ ), lung function and dyspnea. Comparable improvements in DLCO were observed regardless of the severity of disease and the presence of ventilation inhomogeneity. While patients with $V_{A} / T L C<0.8$ improved the DLCO increasing their $V_{A}(177 \pm 69 \mathrm{ml} ; p<0.01)$, patients with $V_{A} / T L C>0.8$ improved their KCO $(8.1 \pm 2.8 \% ; p=0.019)$. The latter had also better baseline lung function and higher improvements in $6 \mathrm{MWT}(14.6 \pm 6.7$ vs. $9.0 \pm 1.8 \% ; \mathrm{p}=0.015)$. Lower DLCO at baseline was associated with lower improvements in 6MWT, the greatest difference being between subjects with very severe and mild DLCO impairment ( $2.7 \pm 7.4$ vs. $14 \pm 2 \%$; $p=$ 0.049). Conclusions: In COPD patients undergoing a PR program, different pathophysiological mechanisms may drive improvements in DLCO, while ventilation inhomogeneity may limit improvements in exercise tolerance.

(c) 2016 S. Karger AG, Base

Prof. Pierachille Santus

Department of Health Science, University of Milan

Pulmonary Rehabilitation Unit, Fondazione Salvatore Maugeri

Scientific Institute of Milan, IRCCS, Via Camaldoli, IT-64-20138 Milano (Italy)

E-Mail pierachille.santus@unimi.it 


\section{Introduction}

In the last decades, pulmonary rehabilitation (PR) has grown in importance as a fundamental part of the management of patients with COPD. As a multidisciplinary intervention, it reduces symptoms, improves exercise tolerance and decreases health care costs $[1,2]$. The improvement of patients' daily life activity and exercise performance represents a major priority of $\mathrm{PR}$, and the disease complexity implies the need for personalized and focused PR programs [2]. Therefore, the initial respiratory functional assessment should be as complete as possible [3] as many pathophysiological variables concur in predicting exercise tolerance in COPD. However, with respect to other measurements, a few studies consider the single breath lung diffusing capacity for carbon monoxide (DLCO) as a routine test during a PR workup. Moreover, the assessment of DLCO with the single breath maneuver allows the measurement of the transfer coefficient for carbon monoxide (KCO) and of the alveolar volume (VA), variables that so far earned limited clinical consideration [4]. While DLCO is a measure of total lung diffusing capacity, the VA, when corrected for total lung capacity (VA/TLC), represents the fraction of accessible inspiratory lung volume and provides valuable information about inspired gas distribution abnormalities and therefore of ventilation inhomogeneity $[5,6]$. In patients with COPD, DLCO represents one of the best predictors of oxygen consumption, exercise performance and intensity of daily physical activity [7-9]. Accordingly, ventilation inhomogeneity predicts reduced maximal exercise capacity better than forced expiratory volume in $1 \mathrm{~s}\left(\mathrm{FEV}_{1}\right)$, and has been shown to limit exercise tolerance causing exercise ventilation inefficiency even in mild and moderate patients with COPD $[10,11]$. The possibility that PR may elicit improvements in DLCO and VA has never been systematically explored; moreover, the relationship between DLCO, VA/TLC and PR outcomes is still unknown. Mota et al. [12] described no changes in DLCO and lung volumes in severe and very severe COPD patients after a 5 -week expiratory muscle training program [12]; the study, however, enrolled only a total of 16 patients and did not include any other exercise or educational training. On the other hand, a recent report described a significant increase in DLCO in severe patients with COPD after an 8-week outpatient PR program. Also in this case, the primary outcome was not DLCO, no subcomponents were measured, and the patients enrolled were 36 [13]. As opposed to heart failure [14], in COPD the KCO is related to the integrity of the alveolar-capillary membrane, and therefore to the extent of emphysema [15], which should constitute an irreversible phenomenon. In this connection, we hypothesize that changes in DLCO following $\mathrm{PR}$, when present, may be driven by an increase in inspiratory accessible lung volume - i.e. VA/TLC. Therefore, the aim of our study was twofold: (1) to explore if PR can induce changes in DLCO in patients with COPD and, if so, to determine which DLCO component is implicated; (2) to explore the relationship between DLCO, KCO and ventilation inhomogeneity and PR-related changes in exercise tolerance, dyspnea and gas exchange.

\section{Materials and Methods}

Study Design

A prospective, observational, multicenter study was performed in three PR units of Fondazione Salvatore Maugeri: Milan (Italy), Telese (Benevento, Italy) and Cassano delle Murge (Bari, Italy) from October 2012 until March 2014.

\section{Patients}

Inpatients and patients in day-hospital setting were consecutively enrolled. Subjects were referred to the unit for a standardized high-intensity PR program conducted according to the ERS/ATS statement recommendations [1]. Patients were all in stable clinical condition. No patients were treated with antibiotics or systemic corticosteroids, and no changes were made to the bronchodilator home treatment prior to enrollment. Inclusion criteria were: a confirmed diagnosis of COPD, with a postbronchodilator forced expiratory volume in the first second to slow vital capacity ratio $<88 \%$ of predicted value (\%pred) for males and $<89 \%$ pred for females according to the lower limit of normal criteria [16] and any degree of airflow limitation; stable clinical conditions at enrollment, and the ability to perform the pulmonary function tests. Exclusion criteria were: impaired cognitive function (Mini-Mental State Examination score <26), a current diagnosis of neoplastic and musculoskeletal diseases, previous lobectomy, a restrictive and mixed obstructive-restrictive ventilatory pattern and patients with a previous history of asthma. Patients that had recently underwent cardiothoracic surgery, with NYHA III or IV functional class heart failure, primitive pulmonary hypertension, diagnosis of vasculitis or other rheumatic disease and severe valvulopathies were excluded too. Patients who had an exacerbation during the PR program were excluded from the study.

\section{Functional Assessment}

Static, dynamic lung volumes and total specific airway resistances $\left(\mathrm{sRaw}_{\mathrm{tot}}\right)$ were assessed by means of a constant-volume body plethysmograph (MasterScreen Body; Erich Jaeger GmbH, Würzburg, Germany). Intrathoracic gas volume (ITGV) was obtained at functional residual capacity, and $s \mathrm{Raw}_{\text {tot }}$ were calculated during tidal breathing. DLCO, KCO and VA were measured with the single breath maneuver (Master Screen PFT System; Jaeger, VIASYS Healthcare, Hoechberg, Germany), assessing the VA by means of the inert gas dilution technique. Lung function testing was performed according to current ATS/ERS recommendations 


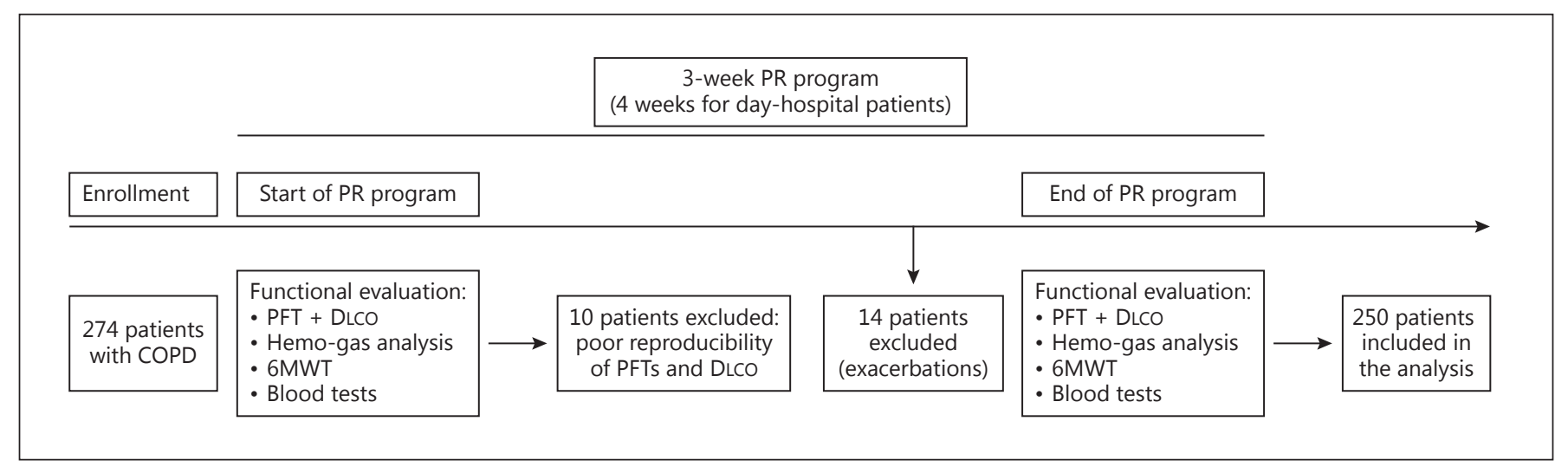

Fig. 1. Study protocol outline.

$[17,18]$. For every patient, the VA measurements were normalized with plethysmographic TLC as suggested by Hughes et al. [5]. The presence of ventilation inhomogeneity was considered as a VA/ TLC $<0.8$ according to the data from Neder et al. [10]. In particular, the study of Neder and colleagues showed that in 69 healthy subjects in $91.4 \%$ of the cases the difference between TLC and VA (\%) was less than $17 \%$; considering that anatomical dead space accounts for about the $2-3 \%$ of TLC, we considered the presence of ventilation inhomogeneity as a VA/TLC ratio $<0.8$. Exercise tolerance was evaluated with the distance covered during a 6-min walking test (6MWT), and dyspnea before and after exercise was assessed by means of the Borg Dyspnea Scale (BDS) according to ATS guidelines [19]. $\mathrm{PaO}_{2}$ and $\mathrm{PaCO}_{2}$ were obtained at rest, sampling the radial artery in room air conditions (GEM Premier 3000; Instrumentation Laboratory, Lexington, Mass., USA). Both lung function and exercise testing were performed while patients were under the effect of bronchodilation therapy, according to their specific therapeutic regimen. The measurements listed above, including height, weight, body mass index and routine blood tests, were assessed at the beginning and at the end of the PR program. Figure 1 shows an outline of the study protocol.

For analysis, patients were categorized both by severity of airway limitation $\left(\mathrm{FEV}_{1} \geq 50 \%\right.$ pred or $<50 \%$ pred) and by presence or absence of ventilation inhomogeneity, (VA/TLC ratio $<$ or $\geq 0.8$ ).

The study was conducted in accordance with the amended Declaration of Helsinki (2013), and each patient gave written, informed consent. The study was approved by the Central Ethics Committee (Fondazione Salvatore Maugeri-717 CEC).

\section{Content of the PR Program}

The PR program had a mean duration of 3 weeks ( \pm 3 days) for inpatients, while for patients in day-hospital setting, it lasted 4 weeks ( \pm 2 days) because the training sessions were not performed during the weekend. At enrollment, patients underwent the assessment of a pulmonologist and a respiratory therapist that tailored the PR program to meet the needs and the specific goals of every single patient. The PR program consisted in: (a) at least one supervised cycle ergometer or treadmill training sessions per day (30 $\min ), 6$ days per week, the intensity of which was set at $60-80 \%$ of maximal workload based on $6 \mathrm{MWT}$ results, and increased during the PR program according to the patient's improvement; oxygen supplementation was provided when $\mathrm{SpO}_{2}$ fell under 90\%; (b) one session of supervised upper and lower limb strengthening exercises and breathing exercises (30 min per day, 6 days a week); (c) inspiratory and expiratory muscle training according to the severity of disease and the initial degree of impairment (20 min per day, 7 days per week); (d) bronchial clearance and cough enhancement techniques (30 min, twice daily, 7 days a week), according to patients' symptoms; (e) bronchodilator therapy optimization aimed at maximization of bronchodilation, with educational interventions for self-management improvement, inhalation therapy teaching for correct administration techniques and breathlessness control; (d) relaxation sessions for reduction of dyspnea and psychological counseling, when appropriate. The intensity of cycle ergometer training was regulated according to heart rate and BDS [2]. Although longer-duration PR programs are associated with better quality of life outcomes [20], the optimal duration in terms of exercise performance improvement is still matter of debate [20]. In some countries like Germany [21] and Italy, the duration of PR programs is limited by insurance companies and monitoring authorities. Thus, in the latter cases, high-intensity PR programs are preferred to low-intensity ones [20,21]. The efficacy of a 3-week PR program in terms of dyspnea, symptoms, lung function and exercise tolerance [21] has been recently confirmed by a retrospective study with a population of 544 very severe COPD patients.

\section{Statistical Analysis}

Data are presented as mean \pm SD unless otherwise stated. The analysis was performed with SPSS 21.0 (IBM SPSS Statistics for Windows, version 21.0; IBM Corp., Armonk, N.Y., USA). Predicted values for lung function variables are from Quanjer [22]. As the literature on the effect of PR on DLCO is scarce, the study was powered considering previous reports that investigated lung volume changes following PR in COPD [23]. Considering a 10\% dropout rate and the need for a subgroup analysis, we set the minimum target number for the study population to be around 200 patients. For lung function tests, the best of three maneuvers was considered for analysis. The $6 \mathrm{MWT}$ was performed once at the beginning and once at the end of the PR program, and the difference of the two tests was considered for analysis. Normal distribution of data was 
Table 1. Patients' functional and clinical characteristics

\begin{tabular}{|c|c|c|c|c|c|c|c|}
\hline Patients, n (\%tot) & 250 & $72(28.8)$ & $178(71.2)$ & & $113(45.2)$ & $137(54.8)$ & \\
\hline Male, n (\%group) & $189(75.6)$ & $54(75)$ & $135(75.6)$ & 0.954 & $73(64.6)$ & $116(84.7)$ & $<0.001$ \\
\hline Age, years & $71.5 \pm 7.4$ & $71 \pm 7.5$ & $71.7 \pm 7.5$ & 0.273 & $72.8 \pm 70.7$ & $70.5 \pm 7.2$ & 0.025 \\
\hline $\mathrm{FEV}_{1}, \%$ pred & $50.5 \pm 20.1$ & $60.7 \pm 20.3$ & $45.3 \pm 18.1$ & $<0.001$ & $68.6 \pm 14.5$ & $35.5 \pm 14.5$ & $<0.001$ \\
\hline $\mathrm{FEV}_{1} / \mathrm{VC}, \%$ pred & $54.4 \pm 15.3$ & $64.3 \pm 11.1$ & $46.4 \pm 12.5$ & $<0.001$ & $65.1 \pm 10.5$ & $45.2 \pm 12.5$ & $<0.001$ \\
\hline GOLD stage I, n (\%group) & $22(8.8)$ & $13(18.1)$ & $9(5.1)$ & $<0.001$ & $22(19.5)$ & & n.a. \\
\hline GOLD stage II, n (\%group) & $91(36.4)$ & $42(58.3)$ & $49(27.5)$ & $<0.001$ & $91(80.5)$ & & n.a. \\
\hline GOLD stage III, n (\%group) & $99(39.6)$ & $13(18.1)$ & $88(49.4)$ & $<0.001$ & & $99(72.3)$ & n.a. \\
\hline Hematocrit, \% & $39.2 \pm 3.9$ & $38.9 \pm 2.8$ & $40.1 \pm 2.5$ & 0.087 & $40 \pm 2.7$ & $39.4 \pm 3.1$ & 0.174 \\
\hline
\end{tabular}

Values are presented as mean $\pm \mathrm{SD}$, where appropriate. Statistical difference is reported for between-group comparisons. BMI = Body mass index; PY = pack years; \%pred = percent of predicted value; GOLD = global initiative for obstructive lung disease; n.a. = not applicable. For other abbreviations refer to text.

assessed by means of the Kolmogorov-Smirnov test. Student's $t$ test for paired data was used to determine statistical significance with 95\% confidence interval (CI) for within-group analysis. Between-group comparisons were assessed normalizing data for baseline values and analyzed by means of analysis of covariance; Bonferroni corrections were applied where appropriate. For comparison of nonnormally distributed data, the Kruskal-Wallis and Mann-Whitney tests were performed, as appropriate. The distribution of GOLD stages was analyzed with the $\chi^{2}$ test. Correlations between lung function and PR outcomes were investigated by means of the Pearson correlation coefficient (r). Variables that showed a significant correlation were used as independent variables in single and multiple linear regression models. Significance was accepted at $\mathrm{p}<0.05$.

\section{Results}

A total of 274 patients (204 males) were enrolled in the study. During the study, 14 patients were excluded because they experienced COPD exacerbations, and 10 patients because of poor repeatability of the lung function tests at baseline; 250 patients were considered for the analysis (fig. 1). Baseline characteristics are reported in tables 1 and 2 .

\section{General Study Population}

After the PR program, all the lung function and gas exchange parameters improved significantly, except for TLC. DLCO and VA/TLC increased, the latter mainly because of an increase in VA (mean \pm SD, $100 \pm 510 \mathrm{ml}$; $\mathrm{p}<$ $0.05)$, while the KCO was unchanged. 6MWT improved by an average of $38.7 \mathrm{~m}$ (95\% CI: 33.8, 47.1; p < 0.001) i.e. $11.5 \%$ compared to baseline, and BDS postexercise was reduced by 1.34 score points ( $95 \%$ CI: $-1.1,-1.6 ; \mathrm{p}=$ 0.018) (table 2).

\section{Analysis by Severity of Airflow Limitation}

One hundred and thirteen patients had a mild-moderate airflow limitation $\left(\mathrm{FEV}_{1} \geq 50 \%\right)$ and 137 patients had severe to very severe disease $\left(\mathrm{FEV}_{1} 50 \%\right)$ (table 1$)$. As expected, all the parameters at baseline were significantly worse in patients with severe COPD (tables 1 and 3). Although both groups showed significant improvements in lung function, exercise capacity and gas exchange after PR (fig. 2), the improvements in IC, RV, ITGV and sRaw $_{\text {tot }}(-4.1 \%$; 95\% CI: 0.6, 8.7; $\mathrm{p}=0.001)$ were significantly larger for severe patients (fig. 2a).

Once again, TLC remained constant. In both cases, DLCO increased due to an improvement in VA/TLC, while there was no significant change in $\mathrm{KCO}$ (fig. 2). 
Table 2. Changes after pulmonary rehabilitation in the general study population

\begin{tabular}{|c|c|c|c|c|}
\hline \multirow[t]{2}{*}{ Variable } & \multicolumn{4}{|c|}{ Study population $(\mathrm{n}=250)$} \\
\hline & pre-PR & post-PR & $\Delta$ post-PR & $\mathrm{p}$ value \\
\hline IC, 1 & $2.0 \pm 0.8$ & $2.17 \pm 0.7$ & $0.18 \pm 0.5$ & $<0.001$ \\
\hline \%pred & $83.5 \pm 29.3$ & $99.1 \pm 27.4$ & $(13.9 \pm 39.4)$ & $<0.001$ \\
\hline $\mathrm{RV}, 1$ & $4.0 \pm 1.3$ & $3.7 \pm 1.4$ & $-0.33 \pm 0.76$ & $<0.001$ \\
\hline \%pred & $165.7 \pm 55.5$ & $159.2 \pm 43.1$ & $(-5.85 \pm 15.8)$ & $<0.001$ \\
\hline $\mathrm{VC}, 1$ & $2.8 \pm 0.8$ & $3.0 \pm 0.6$ & $0.17 \pm 0.39$ & $<0.001$ \\
\hline \%pred & $86.2 \pm 19.7$ & $94.0 \pm 19.2$ & $(7.8 \pm 18.1)$ & $<0.001$ \\
\hline $\mathrm{FEV}_{1}, 1$ & $1.2 \pm 0.5$ & $1.3 \pm 0.6$ & $0.08 \pm 0.32$ & $<0.001$ \\
\hline \%pred & $50.7 \pm 20.3$ & $57.1 \pm 22.6$ & $6.6 \pm 22.4)$ & $<0.001$ \\
\hline TLC, 1 & $6.7 \pm 1.4$ & $6.1 \pm 1.3$ & $-0.06 \pm 0.45$ & 0.410 \\
\hline \%pred & $114.1 \pm 21.3$ & $113.8 \pm 18.9$ & $(-0.3 \pm 7.6)$ & 0.752 \\
\hline ITGV, 1 & $4.7 \pm 1.5$ & $4.4 \pm 1.5$ & $-0.28 \pm 0.78$ & $<0.001$ \\
\hline \%pred & $145.7 \pm 44.4$ & $140.2 \pm 41.6$ & $(-4.24 \pm 14.5)$ & $<0.001$ \\
\hline $\mathrm{sRaw}_{\text {tot }}, \mathrm{kPa} \times \mathrm{s}$ & $3.6 \pm 2.4$ & $3.3 \pm 2.3$ & $-0.30 \pm 1.29$ & $<0.001$ \\
\hline \%pred & $324.8 \pm 214.8$ & $322.1 \pm 211.1$ & $(-2.6 \pm 28.9)$ & $<0.001$ \\
\hline DLCO, $\mathrm{mmol} \times \min ^{-1} \mathrm{kPa}^{-1}$ & $3.7 \pm 1.7$ & $3.58 \pm 1.7$ & $0.12 \pm 0.63$ & 0.004 \\
\hline \%pred & $48.4 \pm 21.1$ & $55.4 \pm 22.6$ & $(6.9 \pm 32.2)$ & 0.003 \\
\hline $\mathrm{VA}, 1$ & $4.6 \pm 1.0$ & $4.7 \pm 1.1$ & $0.1 \pm 0.51$ & 0.008 \\
\hline \%pred & $81 \pm 15.0$ & $84 \pm 15.5$ & $(2.92 \pm 11.2)$ & 0.030 \\
\hline VA/TLC & $0.7 \pm 0.1$ & $0.71 \pm 0.1$ & $(6.0 \pm 16.1)$ & $<0.001$ \\
\hline $\mathrm{KCO}, \mathrm{mmol} \times \min ^{-1} \mathrm{kPa}^{-1} \mathrm{l}^{-1}$ & $0.8 \pm 0.3$ & $0.8 \pm 0.4$ & $0.0 \pm 0.16$ & 0.783 \\
\hline \%pred & $62.0 \pm 25.3$ & $65.5 \pm 27.6$ & $(3.5 \pm 26.2)$ & 0.801 \\
\hline 6MWT, m & $330.3 \pm 121.1$ & $369.6 \pm 122.5$ & $38.7 \pm 55.3$ & $<0.001$ \\
\hline \%pred & $72.4 \pm 25.1$ & $83.6 \pm 26.7$ & $(11.5 \pm 24.2)$ & $<0.001$ \\
\hline BDS before exercise, points & $0.33 \pm 0.99$ & $0.11 \pm 0.96$ & $-0.22 \pm 0.85$ & 0.346 \\
\hline BDS after exercise, points & $4.0 \pm 2.8$ & $2.7 \pm 2.9$ & $-1.34 \pm 2.12$ & $<0.001$ \\
\hline $\mathrm{PaCO}_{2}, \mathrm{~mm} \mathrm{Hg}$ & $42.8 \pm 7.3$ & $41.7 \pm 6.4$ & $-1.13 \pm 3.53$ & 0.002 \\
\hline $\mathrm{PaO}_{2}, \mathrm{~mm} \mathrm{Hg}$ & $70.4 \pm 8.9$ & $72.7 \pm 8.1$ & $2.29 \pm 8.82$ & $<0.001$ \\
\hline Hemoglobin, g/dl & $13.6 \pm 2$ & $13.7 \pm 2.1$ & $0.1 \pm 1.9$ & 0.651 \\
\hline Hematocrit, \% & $39.2 \pm 3.9$ & $39.4 \pm 3.8$ & $0.2 \pm 3.8$ & 0.793 \\
\hline
\end{tabular}

Functional parameters before (pre-PR) and after (post-PR) PR, and their changes after the PR program $(\Delta$ post-PR) in the general study population. Values within parentheses are percent changes from baseline. Each value is presented as mean \pm SD. n.s. $=$ Not statistically significant. For other abbreviations refer to text.

BDS improved similarly by $28.5 \%$ (95\% CI: $-40.9,-16.1$ and $-38.8,-18.1$, respectively; $\mathrm{p}<0.05)$.

\section{Analysis by Ventilation Inhomogeneity}

Seventy-two patients had a VA/TLC $\geq 0.8$, and 178 patients had a VA/TLC $<0.8$ (table 1 ). All functional parameters at baseline were significantly worse in patients with ventilation inhomogeneity, except for $\mathrm{KCO}$ and $\mathrm{PaO}_{2}$, (table 3). Except for TLC, after the PR program, both groups improved their static volumes, although the change was more evident in patients with VA/TLC $<0.8$. Both groups improved their DLCO and 6MWT compared to baseline (fig. 2). However, whilst patients with VA/TLC $\geq 0.8$ improved their DLCO with a significant increase in
$\mathrm{KCO}(+8.1 \%$; $95 \%$ CI: $-0.2,12.8 ; \mathrm{p}<0.05)$ and showed no changes in VA/TLC, patients with ventilation inhomogeneity showed an increase in the VA/TLC ratio, due to an increase in accessible lung volume - VA, $+177 \mathrm{ml}(95 \%$ CI: $+108,+245 ; \mathrm{p}<0.05$ ) - and a decrease in TLC (mean $\pm \mathrm{SD},-100 \pm 490 \mathrm{ml} ; \mathrm{p}<0.05)$, with no changes in KCO. The increase in $6 \mathrm{MWT}$ was significantly higher in patients with VA/TLC $\geq 0.8$ (fig. $3 \mathrm{~b}$ ).

The prevalence of ventilation inhomogeneity at baseline was paralleled by a worsened DLCO, ranging from $35 \%$ in patients with normal DLCO to $95 \%$ in patients with a DLCO $<20 \%$ of predicted value (fig. 4). Patients with a DLCO $<20 \%$ predicted experienced significantly lower improvements in 6MWT when compared with pa- 
Table 3. Baseline functional characteristics of the subgroups

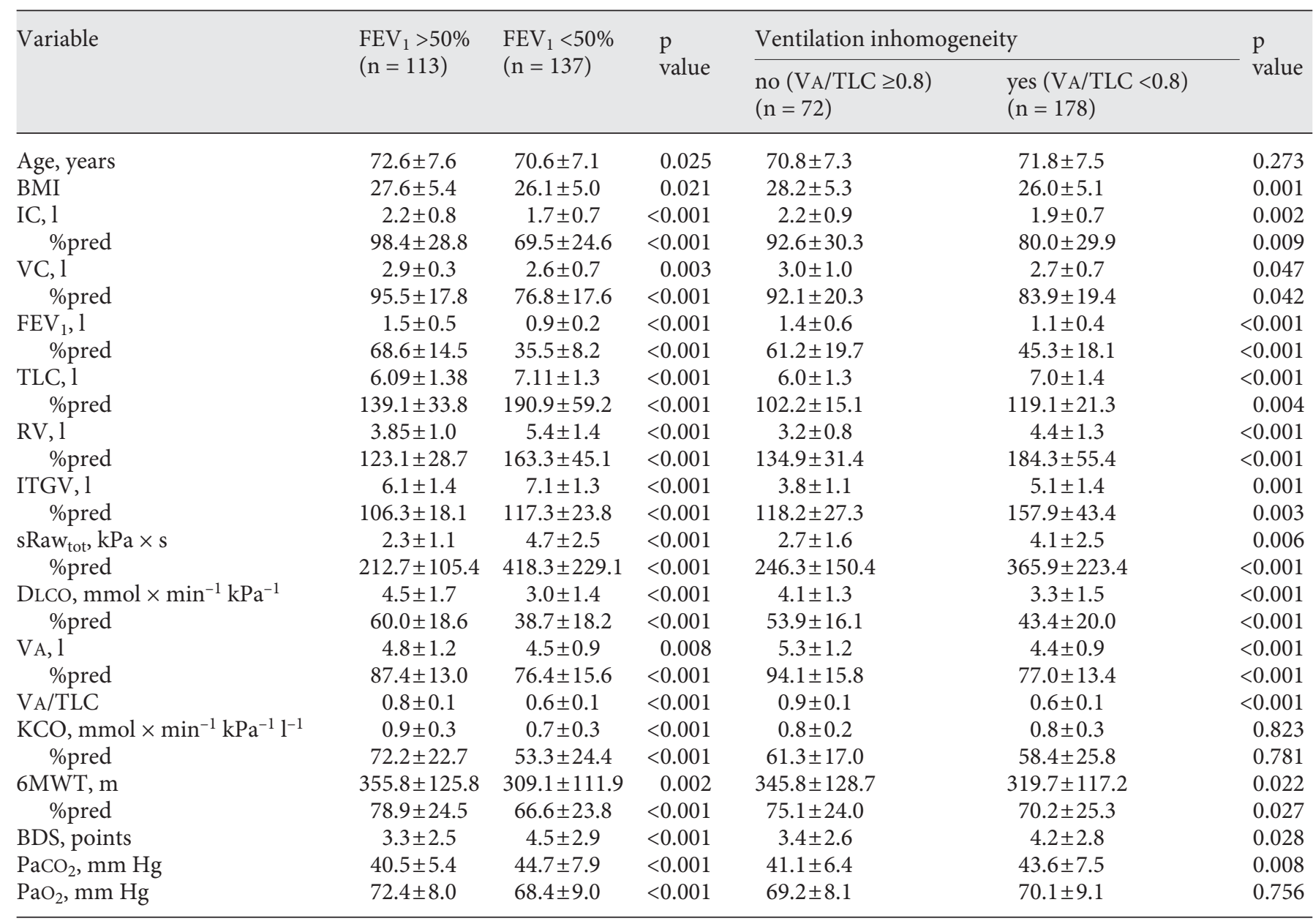

Functional parameters at baseline in patients stratified according to airflow limitation severity and absence or presence of ventilation inhomogeneity $(\mathrm{VA} / \mathrm{TLC} \geq 0.8$ or $<0.8)$. Values are mean $\pm \mathrm{SD}$. For abbreviations refer to text and table 1.

tients with only a mild DLCO impairment $(+2.7 \%$; $95 \%$ CI: $-1.0,6.3$ vs. $+14.1 \%$; 95\% CI: 9.7, 18.4; $\mathrm{p}=0.049$ ) (fig. 4).

\section{Correlation between DLCO Parameters and PR \\ Outcomes}

VA/TLC and KCO had a positive correlation with baseline 6MWT (fig. 5). Patients that presented a VA/ TLC $<0.8$ had a significant linear relationship between the extent of ventilation inhomogeneity and exercise tolerance $(r=0.410)$; the same was not true in patients with no abnormalities in lung volume distribution $(\mathrm{r} \approx 0.0)$. Baseline $6 \mathrm{MWT}$ was also correlated with lung function parameters and end-exercise dyspnea (table 4).
Accordingly, a stepwise regression analysis including DLCO, IC, $\mathrm{FEV}_{1}, \mathrm{RV}, \mathrm{sRaw}_{\mathrm{tot}}$, BDS score after exercise, $\mathrm{PaCO}_{2}$ and $\mathrm{PaO}_{2}$ predicted the baseline $6 \mathrm{MWT}$ with an $\mathrm{R}^{2}=0.38(\mathrm{p}<0.001)$. Improvements in 6MWT, however, correlated only with baseline TLC, VA and BDS after exercise, and were consequently used as independent variables in the second regression analysis.

Only VA added significantly to the model $[F(3,250)=$ 7.593; $\left.\mathrm{R}^{2}=0.08, \mathrm{p}<0.001\right]$. Again, only baseline VA significantly predicted $\triangle \mathrm{PaO}_{2}(\mathrm{~F}=5.595 ; \mathrm{p}=0.019)$.

Changes in VA/TLC and KCO after the PR program appeared to be mostly related to improvements in air trapping and hyperinflation indexes, with a negative significant correlation with changes in RV/TLC $(p<0.001)$, while changes in $\mathrm{PaO}_{2}$ and $\mathrm{PaCO}_{2}$ were significantly cor- 
Fig. 2. Changes in plethysmographic parameters (a) and DLCO, 6MWT and blood gases (b), after PR and in the general study population divided by severity of airflow limitation $\left(\mathrm{FEV}_{1} \geq 50 \%\right.$ pred and $\mathrm{FEV}_{1}$ $<50 \%$ pred). Data are presented as mean \pm standard error. ${ }^{*} \mathrm{p}<0.05$ vs. baseline. Statistical differences for the between-group analysis are indicated where significant. For abbreviations refer to text.

Fig. 3. Changes in plethysmographic parameters (a) and DLCO, 6MWT and blood gases (b) after $\mathrm{PR}$ in patients without ventilation inhomogeneity (VA/TLC ratio $\geq 0.8$ ) and with ventilation inhomogeneity $(\mathrm{VA} / \mathrm{TLC}$ ratio $<0.8)$. Data are presented as adjusted mean \pm standard error. Statistical differences for the between-group analysis are indicated where significant. ${ }^{*} \mathrm{p}<0.05$ vs. baseline. For abbreviations refer to text.
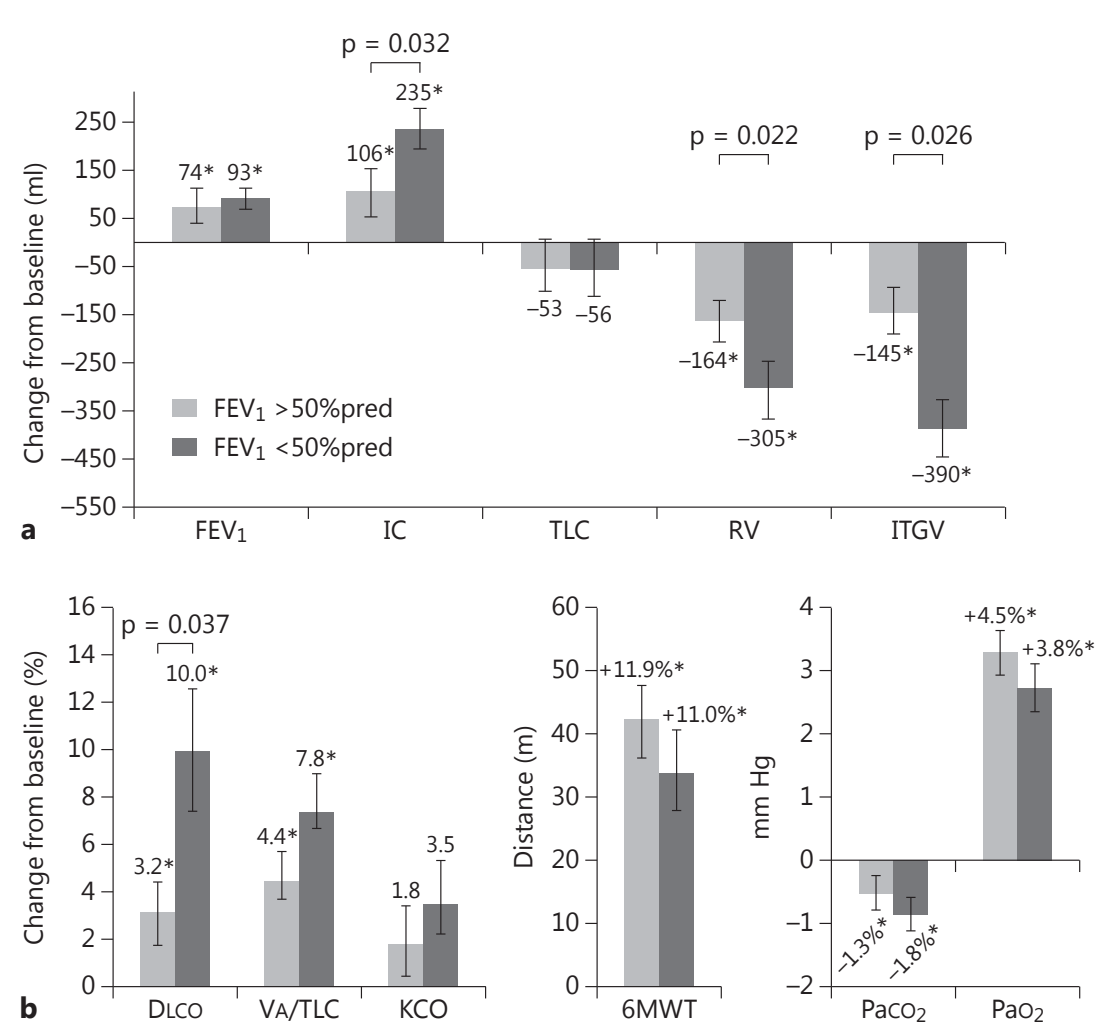

b
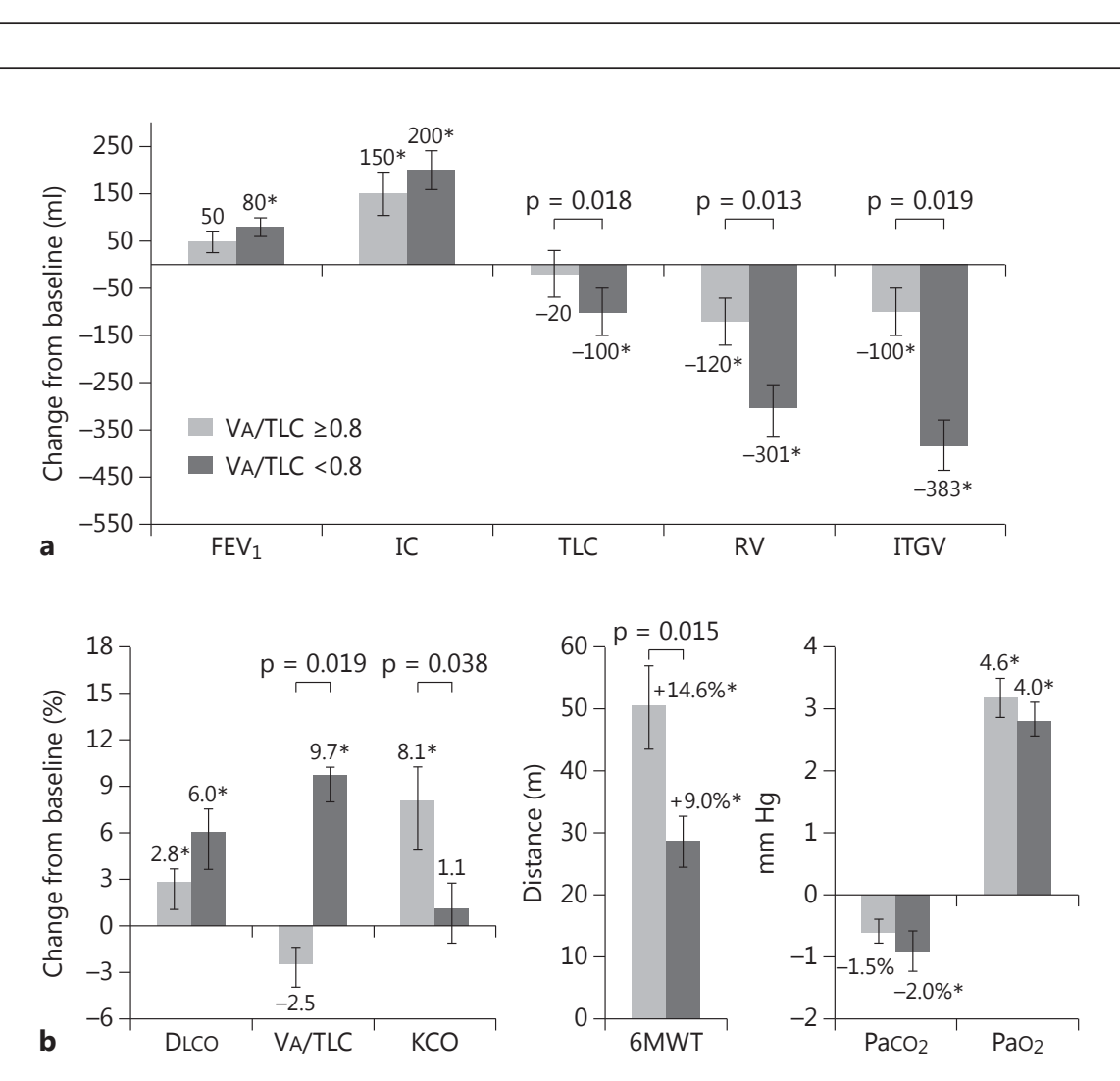
Fig. 4. $\triangle 6 \mathrm{MWT}$ after the PR program based on DLCO severity and prevalence of ventilation inhomogeneity among the general population $(\mathrm{n}=250)$. Absolute changes are reported on top of each column. Data are presented as adjusted means \pm standard error. ${ }^{*} \mathrm{p}<0.05$ vs. baseline. For abbreviations refer to text.
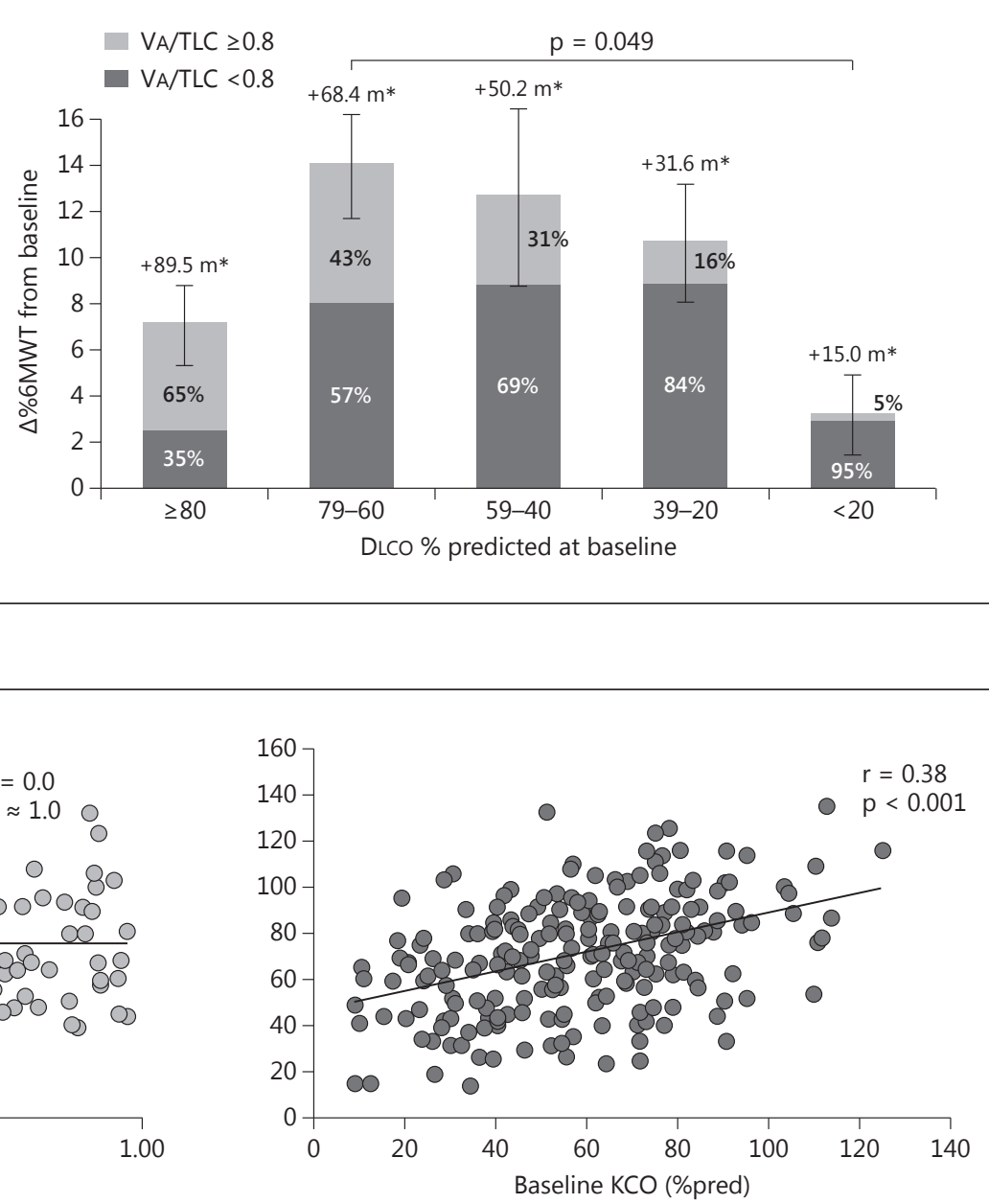

Fig. 5. Linear regression analysis for baseline VA/TLC (left panel) and KCO \%pred (right panel) with the 6MWT at baseline (6MWT \%pred PRE) in the study population $(\mathrm{n}=250)$. Pearson's correlation coefficient and statistical significance is reported. Note that the correlation coefficient is different for patients that have a VA/TLC ratio $\geq 0.8$ and $<0.8$. For abbreviations refer to text.

related particularly with DLCO and KCO (table 5). None of the DLCO parameters were able to predict changes in exercise capacity observed after the PR program.

\section{Discussion}

\section{Main Findings}

The main results of the present study were the following: (1) patients with mild to very severe COPD that undergo a PR program can improve their DLCO, mainly because of an improvement in the accessible lung volume (VA); (2) changes in DLCO, however, appear to be second- ary to different pathophysiological mechanisms in patients with and without ventilation inhomogeneity; (3) patients with severe DLCO impairment and presence of ventilation inhomogeneity appear to experience smaller improvements in exercise tolerance.

The present data show that improvements in DLCO observed in the general study population were associated with an increase in VA/TLC, rather than an improvement in $\mathrm{KCO}$, and patients with both moderate and severe disease appeared to follow the same pattern. However, when divided by presence of ventilation inhomogeneity, DLCO improved in different ways. The group with a normal VA/TLC unexpectedly improved its DLCO by 
Table 4. Correlation between baseline function and changes in exercise tolerance and gas exchange

\begin{tabular}{|c|c|c|c|c|}
\hline \multirow[t]{2}{*}{ Variable } & \multicolumn{4}{|c|}{ Pearson's coefficients $(\mathrm{n}=250)$} \\
\hline & 6MWT \%pred & $\Delta \% 6 \mathrm{MWT}$ & $\Delta \% \mathrm{PaO}_{2}$ & $\Delta \% \mathrm{PaCO}_{2}$ \\
\hline DLCO, \%pred & $0.434^{* *}$ & -0.018 & -0.016 & 0.037 \\
\hline $\mathrm{KCO}$, \%pred & $0.384^{* *}$ & -0.058 & -0.022 & 0.019 \\
\hline VA/TLC, \%pred & $0.298^{* *}$ & 0.035 & 0.117 & 0.020 \\
\hline VA, \%pred & $0.145^{*}$ & $0.222^{* *}$ & $0.130^{*}$ & -0.068 \\
\hline ITGV, \%pred & $-0.384^{* *}$ & 0.104 & 0.014 & -0.072 \\
\hline sRaw $_{\text {tot }}, \%$ pred & $-0.365^{* *}$ & 0.039 & -0.011 & -0.021 \\
\hline IC, \%pred & $0.351^{* *}$ & 0.116 & -0.069 & -0.067 \\
\hline RV, \%pred & $-0.334^{* *}$ & 0.120 & -0.001 & -0.102 \\
\hline $\mathrm{FEV}_{1}, \%$ pred & $0.255^{* *}$ & -0.022 & 0.017 & 0.055 \\
\hline TLC, \%pred & $-0.209^{*}$ & $0.150^{*}$ & -0.063 & -0.075 \\
\hline BDS, end exercise & $-0.301^{* *}$ & $0.139^{*}$ & -0.072 & 0.006 \\
\hline
\end{tabular}

Correlations of baseline lung function parameters and end-exercise dyspnea with baseline 6MWT (6MWT \%pred), changes after PR of $6 \mathrm{MWT}(\Delta \% 6 \mathrm{MWT})$ and blood gases $\left(\Delta \% \mathrm{PaO}_{2}, \Delta \% \mathrm{PaCO}_{2}\right)$. Note that the $\mathrm{r}$ value for the correlation between VA/TLC and 6MWT at baseline represents the association without distinction for patients with and without ventilation inhomogeneity (compare with fig. 4 ). ${ }^{*} \mathrm{p}<0.05 ;{ }^{* *} \mathrm{p}<0.001$. For abbreviations refer to text and table 1 .

increasing $\mathrm{KCO}$; conversely, the patients with ventilation inhomogeneity improved their VA/TLC by increasing their VA.

\section{Improvements in DLCO and Lung Volumes following $P R$}

To the best of our knowledge, so far no study considered DLCO as a primary outcome of PR. No changes in DLCO have been shown by Mota et al. [12], but apart from expiratory muscle training, no other rehabilitative respiratory intervention was administered to the patients enrolled in the study. However, the possibility of an increase in DLCO has been described in a recent paper by Sahin et al. [13], which found that patients with a severe reduction in DLCO had better improvements in dyspnea compared to patients with a mild-moderate DLCO impairment due to blood flow redistribution to lung capillaries. We think that the latter hypothesis might be unlikely to occur because the redistribution of blood during exercise is temporary in nature, and, taking into account the need for an intact pulmonary peripheral vascular bed and the regional inhomogeneity of the DLCO raise during exercise in patients with COPD, unless the lung function test has been performed during or right after the exercise training, the explanation must be different. The findings of the present study support the initial hypothesis that PR in patients with COPD is able to elicit changes in DLCO
Table 5. Correlation between changes in DLCO parameters and function, exercise, dyspnea and gas exchange

\begin{tabular}{lccc}
\hline Variable & \multicolumn{3}{c}{ Pearson's coefficients $(\mathrm{n}=250)$} \\
\cline { 2 - 4 } & $\Delta \% \mathrm{VA} / \mathrm{TLC}$ & $\Delta \% \mathrm{KCO}$ & $\Delta \% \mathrm{DLCO}$ \\
\hline$\Delta \% \mathrm{RV}$ & $-0.552^{* *}$ & $-0.552^{* *}$ & $-0.162^{*}$ \\
$\Delta \% \mathrm{TLC}$ & $-0.498^{* *}$ & 0.030 & 0.020 \\
$\Delta \% \mathrm{RV} / \mathrm{TLC}$ & $-0.230^{* *}$ & 0.002 & 0.104 \\
$\Delta \% \mathrm{ITGV}$ & $-0.495^{* *}$ & $-0.495^{* *}$ & $-0.135^{*}$ \\
$\Delta \% \mathrm{IC}$ & $0.152^{* *}$ & 0.032 & -0.075 \\
$\Delta \% \mathrm{VC}$ & 0.094 & 0.006 & $0.128^{*}$ \\
$\Delta \% \mathrm{FEV}$ & $0.138^{*}$ & 0.026 & $0.129^{*}$ \\
$\Delta \% \mathrm{sRaw}_{\text {tot }}$ & $-0.161^{* *}$ & 0.062 & -0.146 \\
$\Delta \% \mathrm{BDS}$ end exercise & -0.039 & $-0.126^{*}$ & $-0.149^{*}$ \\
$\Delta \% 6 \mathrm{MWT}^{*}$ & 0.061 & 0.070 & 0.056 \\
$\Delta \% \mathrm{PaCO}_{2}$ & -0.011 & $-0.220^{* *}$ & $-0.215^{* *}$ \\
$\Delta \% \mathrm{PaO}_{2}$ & -0.095 & $0.250^{* *}$ & $0.285^{* *}$ \\
\hline
\end{tabular}

Correlations of changes after the PR program in lung functional parameters, dyspnea, 6MWT and blood gases with changes in DLCO parameters. All variables are presented as percent change from baseline. ${ }^{*} \mathrm{p}<0.05$; ${ }^{* *} \mathrm{p}<0.001$. For abbreviations refer to text. 
when an increase in VA takes place. Moreover, the PR program improved static and dynamic lung volumes, exercise tolerance and dyspnea perception regardless of the severity of airflow limitation. Despite the many clinical trials conducted in severe patients with COPD and the contrasting results [21,23-27], our data support the idea that no patients, neither those with moderate disease nor the more severely hyperinflated [28], should be excluded from a PR workout. Our data are in line with recent reports that describe an increase in $\mathrm{FEV}_{1}$ of $99 \mathrm{ml}$ paralleled by a reduction in $\mathrm{RV}$ of $240 \mathrm{ml}$ after a 3-week PR program in severe COPD patients [21], while a recent physiological study in 22 severe COPD patients by de Albuquerque et al. [29] has reported important improvements in static lung volumes after 8 weeks of exercise training, although the difference was not significant. Takigawa et al. [24] studied 225 patients with moderate to severe COPD undergoing a 4- to 8-week PR program. Their data showed significant improvements in $\mathrm{FEV}_{1}, \mathrm{RV}, \mathrm{TLC}$ and VC, paralleled by an increase in $\mathrm{PaO}_{2}$ and a decrease in $\mathrm{PaCO}_{2}$, particularly in severe patients [24].

Our results also confirm that the severity of ventilation inhomogeneity is an important index of reduced exercise tolerance [9-11], and that together with DLCO and static lung volumes it is capable of predicting baseline exercise performance $[7,8]$. None of the variables taken into consideration, however, was able to predict the improvements in 6MWT after the PR program.

\section{The Pathophysiology of Improvements in VA/TLC and $\mathrm{KCO}$}

DLCO has a clear relationship with functional and clinical outcomes in COPD [25-28, 30], and its impairment has been recently described as a good predictor of $6 \mathrm{MWT}$ decline and to be closely correlated with the mean walking intensity $[9,31]$. PR and exercise training are aimed at reducing dynamic hyperinflation and exertional dyspnea, and contrast the decline in exercise tolerance [1, 32]. So far, however, little has been known about the possible changes in DLCO and its role during PR.

The increase in DLCO in our general study population was secondary to an improvement in $\mathrm{VA}$, considering that the elastic lung recoil (TLC) did not change, and was paralleled by an improvement of air trapping and static hyperinflation (table 5). Lung ventilation inhomogeneity, evaluated with the phase III slope of the single breath nitrogen washout test, is closely associated with static lung volumes [33]. This was also true for our group of patients with reduced VA/TLC. A reduction in VA/TLC is mainly due to lung volume regional distribution abnormalities secondary to airflow obstruction $[5,33,34]$, which in COPD has both a fixed component due to parenchymal structural derangement and a partially reversible one due to bronchial inflammation and mucus hypersecretion. An improvement in VA may reflect the promotion of cough efficacy and increased airway clearance which, with respiratory training maneuvers, support lung deflation and recruitment of unventilated lung regions [3537]. Moreover, an increased capacity in self-management [1], implemented with optimization of bronchodilation therapy and educational interventions centered on the correct use of inhaler devices may have played a role in increasing the efficacy of the inhalatory treatment itself, therefore acting on the bronchomotor tone $[38,39]$. The latter hypothesis is sustained by the significant negative correlation present between improvements in VA/TLC and the reduction in RV/TLC and other lung deflation indexes (table 5). Patients with normal and impaired VA/ TLC had comparable KCO values, but the latter group had worse baseline lung function. The lack of KCO changes after PR in this group may be ascribed to the lower density of peripheral lung tissue, and so to a reduced alveolar-capillary surface [40]. The recruitment of lung volume regions poorly useful for gas exchange may have prevented any further KCO increase [38].

Patients without ventilation inhomogeneity also improved their IC, RV and ITGV (fig. 3b); moreover, changes in KCO were significantly correlated with improvements of air trapping indexes. Changes in static lung volumes during PR may be explained by breathing exercise training, inhalatory pharmacological optimization and use of supplemental oxygen when necessary [37, 41]. Those modifications can be responsible for an improvement in pulmonary parenchymal interdependence $[42$, 43] and, as previously pointed out by Weibel's studies on lung morphometry, a regional reduction in air trapping may have a role in the optimization of capillary circulation, allowing the so-called 'angle vessels' to return to a more physiological status, thus increasing the regional gas to blood ratio $[44,45]$, and therefore explaining the increase in KCO, paralleled by an improvement in gas exchange. A reduction in static hyperinflation can be also responsible for an improvement in the lung regional hypoxemic vasoconstriction observed in patients with COPD [41]. The previous hypotheses imply the presence of a preserved alveolar-capillary surface, a circumstance that in this case might be plausible, considering that patients without ventilation inhomogeneity had also better lung function at baseline (table 3). In our study, variations in $\mathrm{KCO}$ were not due to changes in hematocrit (table 2); 
moreover, it is unlikely that in a population without severe cardiac disease and pulmonary arterial hypertension, the changes in DLCO occurred only because of changes in cardiac compliance and contractility, as it has been recently demonstrated in acute conditions in severely hyperinflated patients with COPD [46].

\section{DLCO and Exercise Performance}

Lung ventilation inhomogeneity was also associated with a worse exercise performance and higher dyspnea perception at baseline. Previous reports showed that dynamic hyperinflation [47], a worse DLCO, higher dyspnea at rest with more ventilation/perfusion inhomogeneity during exercise [48] and ventilation inhomogeneity itself are strictly related to exercise performance in patients with COPD $[10,11]$. Furthermore, our data suggest that patients with worse DLCO and ventilation inhomogeneity at baseline had also significantly less improvement in $6 \mathrm{MWT}$ when compared with patients with only mild DLCO impairment or absence of ventilation inhomogeneity (fig. 4). Satta et al. [49] described that in COPD patients, higher values of DLCO are associated with higher muscular concentration of myosin heavy chain type I, the fibers responsible for endurance exercise. The latter, together with better lung mechanics and less exercise-induced dyspnea may be responsible for a better exercise response to PR in patients with normal VA/TLC (fig. 3b, $4)$. On the other hand, lower relative improvements in 6MWT in patients with normal DLCO (fig. 4) may be due to a lower margin of improvement secondary to better baseline conditions and higher level of activity before entering the PR program. However, plethysmographic and DLCO parameters were unsatisfactory predictors of changes in exercise performance. So far, predictors of the response to PR have been a matter of controversial discussion $[8,26,50]$, and our data reflect once more the complexity of the mechanisms implied in exercise training in patients with COPD. Probably, more attention should be directed to the extent of muscular stress and the achievement of lower limb muscle contractile fatigue [51].

\section{Clinical Implications}

The present study shows how a comprehensive PR program is able to improve lung function and DLCO parameters along with exercise tolerance. The possibility that ventilation inhomogeneity and the kind of prevalent DLCO impairment may play a role in determining the response of patients with COPD to PR should stimulate clinicians to perform the best functional assessment possi- ble and thus to relate and to tailor the rehabilitative intervention according to the patient's endotype. Patients that lie on any nuance of the disease severity spectrum, if well framed, should benefit from a personalized rehabilitative intervention.

\section{Study Limitations}

The lack of a control group is a limitation of this study, but the role of PR is so well established that a control group would not be appropriate; moreover, we compared changes in prespecified groups of patients within our study population. Finally, no systematic echocardiographic assessment was performed, and although patients with severe cardiac comorbidities were excluded from the study, the presence of secondary pulmonary hypertension among patients with a low KCO is unknown. This may have conditioned, although to a little extent, the results in this specific group of patients.

\section{Conclusions}

Our study shows that PR in patients with COPD has a positive effect on DLCO regardless of the severity of disease and that changes in DLCO seem to depend on the patient's phenotype and endotype. A lower improvement in exercise tolerance can be secondary to a severe DLCO impairment and to the presence of ventilation inhomogeneity. The clinical long-term importance of the changes in DLCO described in this study, however, are still left to speculation. Future prospective controlled studies would be necessary to confirm our hypotheses and to investigate the possible relation between tailored rehabilitation treatments, DLCO phenotype and lung function impairment. Our data suggest that during PR, DLCO assessment should always be included in the functional workup.

\section{Acknowledgements}

The authors would like to thank Lacala G, PT, Gaudiello G, PT, Ciraudo R, PT, and Alfieri G, PT (Pulmonary Rehabilitation Unit, Fondazione Salvatore Maugeri, IRCCS - Scientific Institute of Milan, Milan, Italy) for their contribution in providing technical support in data acquisition.

\section{Financial Disclosure and Conflicts of Interest}

All the authors declare no competing financial interests. 


\section{References}

1 Nici L, Donner C, Wouters E, Zuwallack R, 13 Sahin H, Naz I, Varol Y, Aksel N, Tuksavul F, Ambrosino N, Bourbeau J, Carone M, Celli B, Engelen M, Fahy B, Garvey C, Goldstein R, Gosselink R, Lareau S, MacIntyre N, Maltais F, Morgan M, O'Donnell D, Prefault C, Reardon J, Rochester C, Schols A, Singh S, Troosters T; ATS/ERS Pulmonary Rehabilitation Writing Committee: American Thoracic Society/European respiratory Society statement on pulmonary rehabilitation. Am J Respir Crit Care Med 2006;173:1390-1413.

$>_{2}$ Spruit MA, Singh SJ, Garvey C, ZuWallack R, $>_{15}$ et al: An official American Thoracic Society/ European Respiratory Society statement: key concepts and advances in pulmonary rehabilitation. Am J Respir Crit Care Med 2013; 188:e13-e64.

3 Papaioannou AI, Loukides S, Gourgoulianis KI, Kostikas K: Global assessment of the COPD patient: time to look beyond FEV1? Respir Med 2009;103:650-660.

4 Fitting JW: Transfer factor for carbon monoxide: a glance behind the scene. Swiss Med Wkly 2004;134:413-418.

5 Hughes JM, Pride NB: Examination of the carbon monoxide diffusing capacity (DLCO) in relation to its $\mathrm{KCO}$ and VA components. Am J Respir Crit Care Med 2012;186:132139.

6 Teculescu DB, Stanescu DC: Total lung capacity in obstructive lung disease: comparative determination by single and multiple breath helium dilution. Bull Eur Physiopat Jwl Respir 1969;5:453-464.

7 Wijkstra PJ, TenVergert EM, van der Mark TW, Postma DS, Van Altena R, Kraan J, Koëter GH: Relation of lung function, maximal inspiratory pressure, dyspnea, and quality of life with exercise capacity in patients with chronic obstructive pulmonary disease. Thorax 1994;49:468-472.

$\checkmark 8$ Gosselink R, Troosters T, Decramer M: Peripheral muscle weakness contributes to exercise limitation in COPD. Am J Respir Crit Care Med 1996;153:976-980.

-9 Louvaris Z, Kortianou EA, Spetsioti S, Vasilopoulou M, Nasis I, Asimakos A, Zakynthinos S, Vogiatzis I: Intensity of daily physical activity is associated with central hemodynamic and leg muscle oxygen availability in COPD. J Appl Physiol 2013;115:794-802.

$\checkmark 10$ Neder JA, O’Donnell CD, Cory J, Langer D, Ciavaglia CE, Ling Y, Webb KA, O'Donnell DE: Ventilation distribution heterogeneity at rest as a marker of exercise impairment in mildto-advanced COPD. COPD 2015;12:249-256.

11 Lopes AJ, Mafort TT: Correlations between small airway function, ventilation distribution, and functional exercise capacity in COPD patients. Lung 2014;192:653-659.

-12 Mota S, Güell R, Barreiro E, Solanes I, Ramírez-Sarmiento A, Orozco-Levi M, Casan $\mathrm{P}$, Gea J, Sanchis J: Clinical outcomes of expiratory muscle training in severe COPD. Respir Med 2007;101:516-524. Ozsoz A: COPD patients with severe diffusion defect in carbon monoxide diffusing capacity predict a better outcome for pulmonary rehabilitation. Rev Port Pneumol 2016, Epub ahead of print.

14 Guazzi M, Reina G, Tumminello G, Guazzi MD: Improvement of alveolar-capillary membrane diffusing capacity with exercise training in chronic heart failure. J Appl Physiol 2004;97:1866-1873.

15 Cerveri I, Dore R, Corsico A, Zoia MC, Pellegrino R, Brusasco V, Pozzi E: Assessment of emphysema in COPD. A functional and radiologic study. Chest 2004;125:1714-1718.

16 Pellegrino R, Viegi G, Brusasco V, Crapo RO, Burgos F, Casaburi R, Coates A, van der Grinten CP, Gustafsson P, Hankinson J, Jensen R, Johnson DC, MacIntyre N, McKay R, Miller MR, Navajas D, Pedersen OF, Wanger $\mathrm{J}$ : Interpretative strategies for lung function tests. Eur Respir J Suppl 2005;26:948-968.

17 Wanger J, Clausen JL, Coates A, Pedersen OF, Brusasco V, Burgos F, Casaburi R, Crapo R, Enright P, van der Grinten CP, Gustafsson P, Hankinson J, Jensen R, Johnson D, Macintyre N, McKay R, Miller MR, Navajas D, Pellegrino R, Viegi G: Standardisation of the measurement of lung volumes. Eur Respir J 2005; 26:511-522.

18 Macintyre N, Crapo RO, Viegi G, Johnson DC, van der Grinten CP, Brusasco V, Burgos F, Casaburi R, Coates A, Enright P, Gustafsson P, Hankinson J, Jensen R, McKay R, Miller MR, Navajas D, Pedersen OF, Pellegrino $\mathrm{R}$, Wanger J: Standardisation of the singlebreath determination of carbon monoxide uptake in the lung. Eur Respir J 2005;26:720735.

19 ATS Committee on Proficiency Standards for Clinical Pulmonary Function Laboratories: ATS statement: guidelines for the six-minute walk test. Am J Respir Crit Care Med 2002; 166:111-117.

20 Beauchamp MK, Janaudis-Ferreira T, Goldstein RS, Brooks D: Optimal duration of pulmonary rehabilitation for individuals with chronic obstructive pulmonary disease - a systematic review. Chron Respir Dis 2011;8: 129-140.

21 Greulich T, Koczulla AR, Nell C, Kehr K, Vogelmeier CF, Stojanovic D, Wittmann M, Schultz K: Effect of a three-week inpatient rehabilitation program on 544 consecutive patients with very severe COPD: a retrospective analysis. Respiration 2015;90:287-292.

22 Quanjer PH: Standardized lung function testing. Bull Eur Physiopathol Respir 1983;19: 22-61.

-23 Altenburg WA, de Greef MH, ten Hacken $\mathrm{NH}$, Wempe JB: A better response in exercise capacity after pulmonary rehabilitation in more severe COPD patients. Respir Med 2012;106:694-700.
24 Takigawa N, Tada A, Soda R, Takahashi S, Kawata N, Shibayama T, Matsumoto $\mathrm{H}$, Hamada N, Hirano A, Kimura G, Okada C, Endo S, Yamashita M, Date H, Takahashi K: Comprehensive pulmonary rehabilitation according to severity of COPD. Respir Med 2007;101:326-332.

25 Martinez FJ, Foster G, Curtis JL, Criner G, Weinmann G, Fishman A, DeCamp MM, Benditt J, Sciurba F, Make B, Mohsenifar Z, Diaz P, Hoffman E, Wise R; NETT Research Group: Predictors of mortality in patients with emphysema and severe airflow obstruction. Am J Respir Crit Care Med 2006;173: 1326-1334.

26 Crisafulli E, Venturelli E, Biscione G, Vagheggini $\mathrm{G}$, Iattoni A, Lucic S, Ambrosino $\mathrm{N}$, Pasqua F, Cesario A, Clini EM: Exercise performance after standard rehabilitation in COPD patients with lung hyperinflation. Intern Emerg Med 2014;9:23-31.

$\longrightarrow 27$ van Ranst D, Otten H, Meijer JW, van 't Hul AJ: Outcome of pulmonary rehabilitation in COPD patients with severely impaired health status. Int J Chron Obstruct Pulmon Dis 2011; 6:647-657.

28 Vagaggini B, Costa F, Antonelli S, De Simone C, De Cusatis G, Martino F, Santerini S, Paggiaro P: Clinical predictors of the efficacy of a pulmonary rehabilitation program in patients with COPD. Respir Med 2009;103:12241230.

29 Albuquerque AL, Quaranta M, Chakrabarti B, Aliverti A, Calverley PM: Exercise performance and differences in physiological response to pulmonary rehabilitation in severe chronic obstructive pulmonary disease with hyperinflation. J Bras Pneumol 2016;42:121129.

30 Dubois P, Machiels J, Smeets F, Delwiche JP, Lulling J: CO transfer capacity as a determining factor of survival for severe hypoxaemic COPD patients under long-term oxygen therapy. Eur Respir J 1990;3:1042-1047.

31 Díaz AA, Pinto-Plata V, Hernández C, Peña J, Ramos C, Díaz JC, Klaassen J, Patino CM, Saldías F, Díaz O: Emphysema and DLCo predict a clinically important difference for 6MWD decline in COPD. Respir Med 2015; 109:882-889.

32 Santus P, Bassi L, Radovanovic D, Airoldi A, Raccanelli R, Triscari F, Giovannelli F, Spanevello A: Pulmonary rehabilitation in COPD: a reappraisal (2008-2012). Pulm Med 2013;2013:374283.

33 Gennimata SA, Palamidas A, Karakontaki F, Kosmas EN, Koutsoukou A, Loukides S, Koulouris NG: Pathophysiology of evolution of small airways disease to overt COPD. COPD 2010;7:269-275.

34 Milic-Emili J, Pecchiari M, D’Angelo E: Pathophysiology of chronic obstructive pulmonary disease. Curr Resp Med Rev 2008;4: 249-256. 
35 Calverley PMA, Koulouris NG: Flow limitation and dynamic hyperinflation: key concepts in modern respiratory physiology Eur Respir J 2005;25:186-199.

36 Macklem PT: Therapeutic implications of the pathophysiology of COPD. Eur Respir J 2010; 35:676-680.

37 Onodera A, Yazaki K: Effects of a short-term pulmonary rehabilitation program on patients with chronic respiratory failure due to pulmonary emphysema. Nihon Kokyuki Gakkai Zasshi 1998;36:679-683.

- 38 Baldi S, Fracchia C, Bruschi C, Dore R, Maestri R, Brusasco V, Pellegrino R: Effect of bronchodilatation on single breath pulmonary uptake of carbon monoxide in chronic obstructive pulmonary disease. Int J COPD 2006;1:477-483.

39 Santus P, Radovanovic D, Di Marco F, Raccanelli R, Valenti V, Centanni S: Faster reduction in hyperinflation and improvement in lung ventilation inhomogeneity promoted by aclidinium compared to glycopyrronium in severe stable COPD patients. A randomized crossover study. Pulm Pharmacol Ther 2015; 35:42-49.

40 Barjaktarevic I, Springmeyer S, Gonzalez X, Sirokman W, Coxson HO, Cooper CB: Diffusing capacity for carbon monoxide correlates best with tissue volume from quantitative CT scanning analysis. Chest 2015;147: 1485-1493.
41 Rossi A, Aisanov Z, Avdeev S, Di Maria G, Donner CF, Izquierdo JL, Roche N, Similowski T, Watz H, Worth H, Miravitlles M: Mechanisms, assessment and therapeutic implications of lung hyperinflation in COPD. Respir Med 2015;109:785e802.

42 Paré PD, Mitzner W: Airway-parenchymal interdependence. Compr Physiol 2012;2: 1921-1935.

$43 \mathrm{Ma} \mathrm{B}$, Breen B, Bates JH: Influence of parenchymal heterogeneity on airway-parenchymal interdependence. Respir Physiol Neurobiol 2013;188:94-101.

44 Weibel ER: Functional morphology of lung parenchyma; in American Physiological Society (ed), Fishman AP, Macklem PT, Mead J, Geiger SR (curators): Handbook of Physiol ogy, Section III: The Respiratory System, vol 3: Mechanics of Breathing; Part I: Morphology of Lung Parenchyma. Bethesda, American Physiological Society, 1986, pp 89-111.

45 Weibel ER: The Pathway for Oxygen. Structure and Function of the Mammalian Respiratory System. Cambridge, Harvard University Press, 1984.
6 Santus P, Radovanovic D, Di Marco S, Valenti V, Raccanelli R, Blasi F, Centanni S, Bussotti M: Effect of indacaterol on lung deflation improves cardiac performance in hyperinflated COPD patients: an interventional, randomized, double-blind clinical trial. Int J Chron Obstruct Pulmon Dis 2015;10:19171923.

47 Chen R, Lin L, Tian JW, Zeng B, Zhang L, Chen X, Yan HY: Predictors of dynamic hyperinflation during the 6-minute walk test in stable chronic obstructive pulmonary disease patients. J Thorac Dis 2015;7:1142-1150.

48 O'Donnell D: Breathlessness in patients with severe chronic airflow limitation. physiologic correlations. Chest 1992;102:824-831.

49 Satta A, Migliori GB, Spanevello A, Neri M, Bottinelli R, Canepari M, Pellegrino MA, Reggiani C: Fibre types in skeletal muscles of chronic obstructive pulmonary disease patients related to respiratory function and exercise tolerance. Eur Respir J 1997;10:28532860.

50 Garrod R, Marshall J, Barley E, Jones PW: Predictors of success and failure in rehabilitation. Eur Respir J 2006;27:788-794.

- 51 Burtin C, Saey D, Saglam M, Langer D, Gosselink R, Janssens W, Decramer M, Maltais F, Troosters T: Effectiveness of exercise training in patients with COPD: the role of muscle fatigue. Eur Respir J 2012;40:338-344. 